\title{
Development of Organizing and Economic Measures for Monitoring the Cost of Construction Resources
}

\author{
Dmitriy Silka ${ }^{1, *}$ \\ ${ }^{1}$ Moscow State University of Civil Engineering,26, Yaroslavskoye shosse, Moscow,129337, Russia
}

\begin{abstract}
Resources monitoring in the market economy is carried out to determine current market prices. Market pricing depends on a huge list of factors and in each case is carried out in a wide range of initial values with high probability assumptions. This approach is based on a set of organizational and economic mechanisms allowing tracking not potential, but real purchase and sale of construction resources. Systematization the received information allows planning and implementation of state construction contracts in the field of transport and other dispersed construction.
\end{abstract}

\section{Introduction}

Infrastructure construction, which among others includes creating transport facilities in the form of various means of communication, is highly capital-intensive and geographically dispersed. A considerable amount of these projects is carried out by the state, as based on experience of many countries, only the state is able to implement projects with a payback period of a few decades. Moreover, the state centrally accumulates budgets, which allows long-term financing. In other cases, projects are carried out using schemes of public-private partnership.

\section{Methods}

Scientific studies of the author have shown that the cost of building an effective way of monitoring resources can be organized through the creation of a specialized state body "Rosresurs". Organization of monitoring the cost of construction resources involves the creation of special infrastructure, which is based on a number of the following activities [1]:

1. To arrange public procurement, Rosresurs and operators of online trading platforms define that all the companies expected to participate in public procurement, as well as developers of accounting software receive a public procurement participant certificate in Rosresurs institution.

2. To get the certificate, a company shall mention its name, geographic coordinates of locations (warehouses) of shipment of construction resources (if any), types of products they sell and other information defined by Rosresurs.

*Corresponding author: w220@yandex.ru 
3. Operators of trading platforms establish requirements meaning that all state contracts, for which an auction is held, include the requirement that a party signing a state contract, as well as parties supplying construction resources involved to fulfill the state contract have Rosresurs certificate.

4. Rosresurs institution continuously provides information about the enterprises that have received a certificate of participation in state procurement to operators of trading platforms through online communication channels [2].

5. Operators of trading platforms (at registration of participants using computerized algorithms (requests from Rosresurs) and without additional actions by a participant) check if they have the relevant certificates. If the check result is negative, a participant registration is technically rejected.

16. General contractors having signed a state contract undertake to prove their economic activities through providing information to Rosresurs state operator by transferring data identifying the facts of buying material resources, which at the level of technical and organizational mechanisms is implemented in the following manner:

6.1. A general contractor established requirements for its suppliers about the need to obtain a certificate of public procurement participant.

6.2. A general contractor when carrying out trade transactions of procurement of construction resources demands to provide (as part of shipment documents) consignment notes including data identifying the certificate of public procurement participants shown using a generated QR-code. In addition, this code includes the following information:

- Number of a state contract, under which the material resource is supplied;

- Supplier ID (taking into account that it is registered in Rosresurs system and has a corresponding participation certificate);

- Code designation of goods in accordance with OKPD2;

- Value of goods, including VAT;

- The goods unit of measure;

- Volume of delivery;

- Date of delivery;

- Geotag of a supplier's location (geographic coordinates in the form corresponding to the format of the international standards).

6.3. Data in QR-code format are included using a special application in the accounting software (1C, Galaktika, etc.). In its turn, to create such an application, Rosresurs operator provides developers of accounting programs with special specifications, and based on the results of successful testing of the implemented solution certifies corresponding accounting software and its developers (see par. 1 above) [3].

6.4 Accounting software developers inform their customers about the possibility of receiving an additional module that allows creating special forms of consignment notes including the mechanism of encoding the information in QR-code format.

7. After receiving commodity values and accompanying documents, including consignment notes, a general contractor scans the QR-code and automatically transfers the information to the database of Rosresurs state operator. At that, among others, information about specific names of material resources, their cost and geographical location of shipment get into Rosresurs' database.

8. Algorithms of Rosresurs' information system (in the background mode) check information received from general contractors for the presence in its own database about suppliers of construction resources certified before, that have been declared by general contractors.

9. If a general contractor provides to Rosresurs' database data without information about certified suppliers of construction resources, such information is rejected by the system. 
10. A general contractor or another company being a party to the state contract undertakes to regularly enter information about acquired material resources into the database of Rosresurs. Upon completion of the contract, Rosresurs database should have information about construction resources of the general contractor of at least $50 \%$ of the contract value.

11. If at the time of the contract completion, a general contractor has not presented information on the type and cost of used construction resources, its certificate is cancelled, and it is not admitted to participate in new public procurement. Information about missing certificate is automatically transferred to operators of trading platforms of public procurement [4].

12. A general contractor technically cannot more than once upload information to the database of Rosresurs on the same consignment note for accumulation of $50 \%$ of resources cost on a specific contract (to get around the system requirements and to minimize its work). This protection mechanism is implemented in the application of accounting software, developers of which get a corresponding certificate and bear responsibility. Violations by these developers are also prevented by the certificate revocation. Certificates, mechanisms for their verification, certificates turnover are carried out online only.

The scheme of interaction between participants of the value monitoring, as well as the main methods of interaction are shown in Fig.1. According to this scheme, an unlimited number of construction resources used in the transport and infrastructure, industrial, civil construction, etc. are followed and monitored. For the purposes of transport construction, Rosresurs state authority cooperates with the Ministry of Transport of the Russian Federation, the Federal Road Agency "Rosavtodor" and other agencies responsible for transport construction. For the purposes of industrial construction, "Rosresurs" cooperates with the Ministry of Industry and Trade of the Russian Federation. For the purposes of civil construction - with the Ministry of Construction and Housing and Communal Services of the Russian Federation. The purpose of such interactions is regular updating information guides about construction resources, assigning codes and other attributes to them to be included in a unified database and monitored after that [5].

\section{Results}

In addition to the above, transport construction at the design studies stages requires considering transportation costs for delivery of different goods and resources to the construction site. This task is necessary for any type of construction, but in the field of transport facilities construction there is a number of additional conditions and requirements. Unlike during building a house, during construction a railroad or a motor road, a construction site is not fixed. Therefore, it is impossible to rely on unified expenses for delivering construction material to the site. As the construction site moves, material procurement costs will always change. If we solve the problem of transportation costs for material supply for transport construction, the implemented mechanisms would also be useful for other types of construction, including cases, where construction site is stationary $[6]$.

Creating a transportation cost accounting mechanism at supplying a construction site with material resources is carried out at implementation of the method of monitoring heavy trucks. The Russian Federation has a specific order of mandatory supplying certain vehicles with satellite navigation devices. The relevant regulatory documents are:

- Presidential Decree of May 17, 2007, N 638 "On using Glonass global navigation satellite system for socio-economic development of the Russian Federation";

- Russian Federation Government Resolution of August 25, 2008, N 641 "On equipping vehicles, equipment and systems with GLONASS or GLONASS/GPS" satellite navigation 
equipment;

- Order of the Ministry of Transport of the Russian Federation of March 9, 2010, N 55 "On approval of the list of types of motor vehicles used for transportation of passengers and dangerous goods to be equipped with GLONASS or GLONASS/GPS satellite navigation equipment";

- Federal Law of December 28, 2013, N 395-FL "On the state automated information system "ERA-GLONASS" [7].

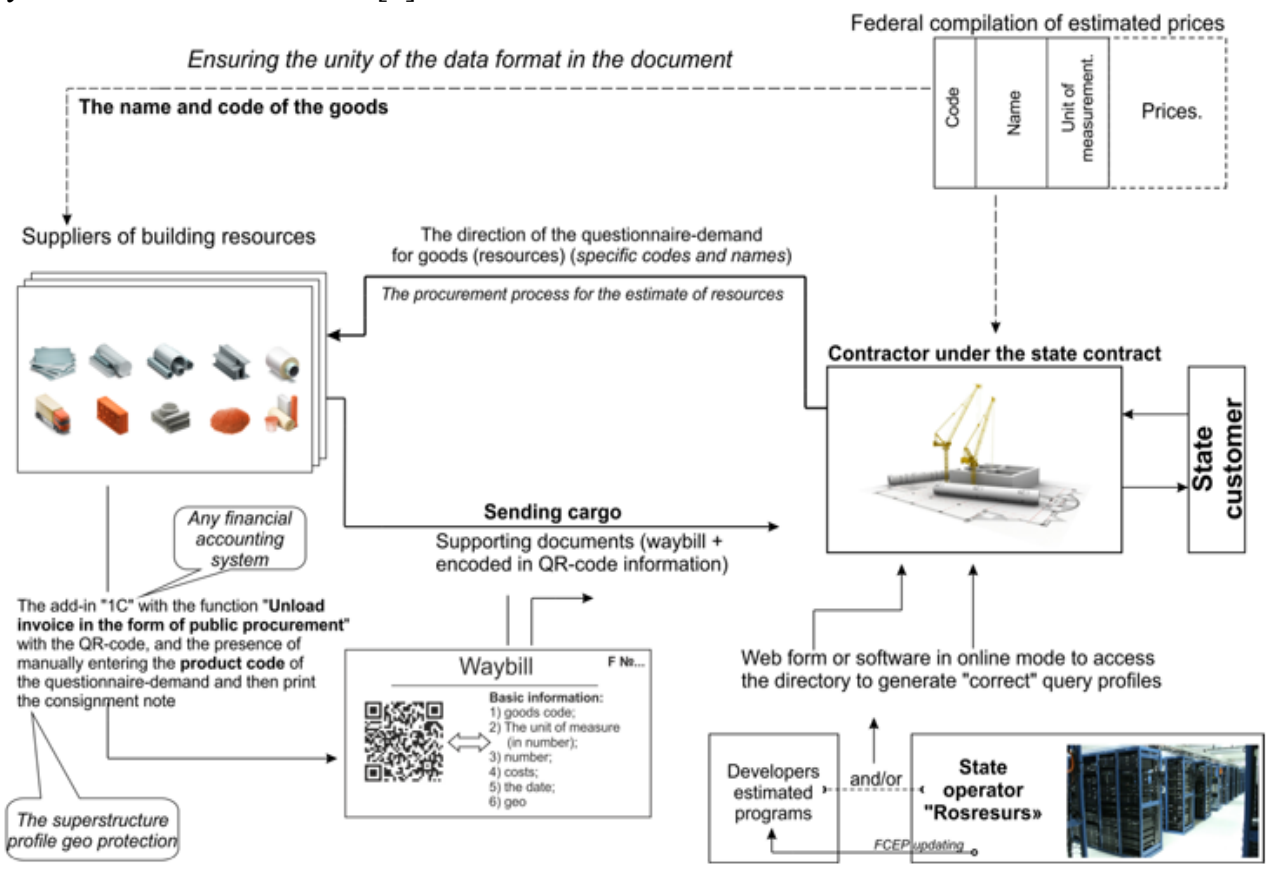

Fig. 1. Flow chart of collecting information on the construction resources cost.

Currently, satellite technologies have not yet revealed their full potential. Therefore, one of the areas of their application is tracking transportation of material resources by heavy trucks. Many companies engaged in transportation by trucks or generally in logistics process, equip their trucks with tachographs. Tachograph is a control device installed on vehicles. It is intended for registration of speed, work and rest schedule of drivers and crew members. In Russia, buses with more than eight seats and trucks with a permissible gross weight of over 3.5 tons (Order the Ministry of Transport of Russia of February 13, 2013, No. 36) should be equipped with tachographs in order to ensure safe conditions. The tachograph is mandatory for M2, M3, N2, N3 class vehicles. Equipping vehicles with control devices should be carried out in accordance with the regulatory documents. An important feature of modern tachographs is a module registering coordinates of a vehicle movement.

Satellite monitoring of transport is based on administrative regulatory measures, but is also very attractive for private business within the own initiatives. It allows obtaining the following results:

- Improving a company competitiveness;

- Minimization of costs for service and maintenance of vehicles;

- Improving a company economic performance through preventing downtime, loss of working hours, unauthorized fuel drains;

- Improving quality of fulfilling contracts provided by vehicles operation;

- Improving management and maintenance efficiency; 
- Optimization of various services of a company, including traffic control service;

- Improving safety and accuracy of vehicles traffic;

- Improving safety of road users, drivers and staff on the way;

- Improving prediction accuracy when planning fulfilling works on contracts provided by vehicles operation, etc.

From each company car equipped with a tachograph, data are regularly downloaded and entered into the local database. Persons responsible for transport in a company may - based on analysis of tachograph data - find the cost of goods transportation per unit of time, distance, etc. Such data have great practical value for the federal cost monitoring, since they contain actual data on the cost of delivery of material resources and may be widely applied in the design stages of facility construction as reference data. Workers are also brought to the construction sites. Buses equipped with tachographs also allow collecting information about the norms of expenses for transportation of labor force [8].

Thus, satellite monitoring infrastructure being currently actively developed carries great practical value for collection of reliable information on movement of goods. The technical aspect of this infrastructure is ready to fulfill the required tasks. At the same time, we have examples when the state could solve organizational issues as well, and created an effective model of vehicle tracking. In accordance with the requirements of Orders of the Federal Service for Alcohol Market Regulation (FSAR) of September 7, 2012, No. 256 and No. 258 , if we consider traffic volume, market participants will not be able to obtain a license for transportation of alcohol, if vehicles transporting alcohol are not equipped with special onboard GLONASS equipment. Currently, the following alcohol producers' vehicles are equipped with GLONASS onboard equipment: "Biotrans", "Peresvet", "Talvis", "KIBIH", "TransAlko" and many others. In the central office of the Federal Service for Alcohol Market Regulation, they created a monitoring service controlling in real time alcohol transportation by routes declared by manufacturers before. In particular, the following systems are used to fulfill these tasks: RAR1 - a system for monitoring location and data collection on the volume of alcohol/product in a tank of a truck carrying alcohol and other vehicles carrying alcohol products. RAR2 - a system for controlling the process of filling and draining alcohol/product from a tank [9].

The systems together ensure control and allow tracking in real time a wide range of monitored parameters of the process of transportation of alcohol and alcohol-containing products: volume, temperature, filling/draining, etc.; ensure maximum transparency of transportation of alcohol products, thus excluding any manipulation with changing temperature conditions in tanks or unauthorized draining at all stages of transportation.

This example of sectoral management clearly evidences that if a problem and objectives to be achieved are correctly identified, the satellite monitoring systems can solve a wide range of problems of transportation analysis, including collecting reference information throughout the country for using at the stages of planning and design of construction

The monitoring mechanism being a base of the proposed federal cost monitoring concept contains a lot of tasks to be solved for the coordinated work of all its components. Development of computer, communication technologies, and information technologies is complemented by institutional mechanisms, which as a whole allows identifying and solving a new class of problems. Implementation of such a monitoring into the industry management system should result in triggering of enforcement mechanisms allowing forcing and/or motivating various business entities for targeted collection of data on the cost of the acquired resources and transferring them to Rosresurs database. These results are achieved by amending the federal contract system (Federal Law No 44). In particular, we introduce obligations of interaction of state customers and state contractors with Rosresurs state authority. A state customer is motivated by certain obligations and their implementation to the higher state authority. Commercial enterprises being state contractors 
are motivated to interact by regulating relations within certification, provided bank guarantees, lists of companies excluded from public procurement, etc.

Companies involved in public procurement and fulfilling their obligations have a confirmed and valid certificate of a public procurement participant. If a participant violates its obligations, it loses its certificate, and in case of financial loss by a state customer, bank guarantee may be applied, which allows insuring the risks caused by violations of contractors [10].

The main result of introducing this system into industrial operation is enabled resource method of calculation of construction costs. This method differs from others by the fact that it is based on resources prices as of the date of construction work planning. Currently this method is the most accurate. The method uses current cost of material and technical, as well as labor resources. Everything related to the cost of material resources, the cost of transporting them to the construction site, as well as the cost of transportation of labor resources is covered by the cost monitoring method. Actually, the costs of technical resources, equipment, and defining them is a different type of task. Such resources belong to fixed assets; they are acquired for a long period and are not directly related to a particular construction object, but may be used on various construction sites. Information about the cost of these resources is also accumulated in Rosresurs database, but collection of such information is carried out using a different set of approaches. It can be direct contacts with companies, manufacturers, dealers, suppliers of machinery and equipment by analyzing their websites and other information sources. A regional network of construction pricing agencies can help greatly in this issue. Their tasks may include analysis of estimates for the projects implemented in the region, systematization of information on used equipment, machinery and devices and transferring to Rosresurs database. Also regional authorities may, within already collected and processed lists of machines and equipment, collect information about their cost [11].

\section{Discussion}

The cost monitoring system has practical utility in others spheres as well. Based on studying geography of using certain resources types, it is possible to define the resource requirements in relation to location, to assess the potential of investing in production of types of material resources, to define measures of support of construction materials industry within regional and federal programs. Information about the cost of construction resources, and - as a result - about the fact of their use allows understanding which resources are actively used at construction sites, and which are out of use and no longer need monitoring them. Such updating Rosresurs state agency's database allows updating estimate standards, and other reference materials used to calculate preliminary estimates [12].

Information about the cost of construction resources allows analyzing activity of business entities in general. If a particular enterprise is defined in the cost monitoring system as a supplier, this information may be useful for the tax authorities controlling this enterprise.

In addition, it is possible to track the levels of distribution of certain resources, knowing who exactly produces such a resource. As a result, we reduce the initial maximum contract price for the corresponding material resources. Such measures may be taken by regional authorities, various state bodies aiming at improving the efficiency of procurement operations. If for example, procurement is not typical, but differs significantly in its volume and cost from others carried out at that time, then defining a real price even in manual mode can provide very good results [13]. 


\section{Conclusion}

The approach of monitoring the cost of construction resources presented in the article allows making a conclusion about its practical relevance and feasibility. The federal cost monitoring, as confirmed by the above analysis, is a fundamentally new approach in information and reference support of construction design. The needs of the state, customers and contracting companies' services are actually satisfied at the level of new-generation solutions. The combination of the construction resources cost monitoring mechanisms is effectively integrated into the economic mechanism and is useful for a variety of types of construction and businesses. In fact, standard accounting documents are used for initial information collection. The study of modern features of information technologies, methods of satellite navigation and objects surveillance and implement methods of their application confirmed the forward-looking importance of solutions proposed in the article. The possibility not only to track the cost of resources, but also to monitor transportation costs, leads to the conclusion that the system is particularly useful for a company dealing with transport construction and other objects of infrastructure construction, where a construction object is not stationary. The priority of meeting the interests and goals of transport construction at creating the cost monitoring system entails the maximum requirements to the monitoring system. Meeting the requirements of transport construction automatically determines meeting the interests of designers also from other spheres of construction, where a construction object is stationary.

\section{References}

1. A.A. Gorobnyak, Economy and Entrepreneurship, 8, 618-621 (2014)

2. Z.I. Ivanova, O.V. Yudenkova, A.D. Ishkov, E.A. Shnyrenkov, International Education Studies. 5, 232-239 (2015)

3. A.D. Ishkov, T.N. Magera. Procedia Engineering, 117, 148-153 (2015)

4. M.I. Kamenetskii, N.Y. Yaskova, Studies on Russian Economic Development, 26(2), 124-131 (2015)

5. S.I. Kuvshinova, I.E. Alpackaya, Topical issues of science collection of articles of the International scientific-practical conference, 121-123. (2014)

6. Y.V. Larionova, S.A. Pavlova, Life Science Journal, 12, 650 (2014)

7. O.V. Papelnuk, S.V. Romashova, Economy and Entrepreneurship, 11-2 598-600 (2013)

8. N.Y. Yaskova, Scientific Review, 9, 505-507 (2013)

9. V.S. Kanhva, Economy and Entrepreneurship, 5-2, 902-905 (2015)

10. V.V. Sokolov, N.Y. Yaskova, Scientific Review, 6, 605-609 (2012)

11. Y. Panibratov, A. Larionov, Applied Mechanics and Materials, 8, 725-726 (2015)

12. Y. Panibratov, A. Larionov, World Applied Sciences Journal, 13, 144-148 (2013)

13. N.Y. Yaskova, D.N. Silka, Business activity management in a mixed construction sector, MGSU, Moscow, (2013) 